\title{
Epidermoid Cyst of Tongue
}

\author{
Choubarga Naik, ${ }^{1}$ Nilamadhab Prusty ${ }^{1}$ \\ Department of Dentistry, VSS Medical College, Burla, Odisha, 768017, India.
}

\begin{abstract}
Epidermoid cyst occurring within the tongue is rare. A 5 year old male child was brought to OPD with a tongue mass which was gradually increasing in size. There was associated difficulty in speech and mastication as the swelling increased in size. Intraoral examination revealed moderately tender, fluctuant and enlarged tongue. A diagnosis of dermoid cyst was made and the patient was booked for surgery. Excision of the cyst was done under general anaesthesia. Post-operative histopathology was done. The histopathological findings confirm the diagnosis of an epidermoid cyst, characterized by the presence of: (I) a cyst cavity lined by stratified squamous epithelium with keratinization on the surface; and (II) connective tissue with a mild inflammation. The proposed treatment was considered successful as the case was solved and there was no recurrence.
\end{abstract}

Keywords: dermoid; epidermoid cyst; tounge.

\section{INTRODUCTION}

Epidermoid and dermoid cysts are nonodontogenic cyst lesions. ${ }^{1}$ They are rare lesions derived from germinal epithelium. While a dermoid cyst has an epidermal lining with skin adnexa such as hair follicles and sebaceous and sudoriparous glands, the epidermoid cyst contains no such adnexa. These cysts are usually sole lesions. ${ }^{2,3}$ It is suggested that these cysts are derived from epithelial remains from the closure process of the first and second branchial arches. ${ }^{4}$ Particularly in the tongue region, these lesions may be formed by remains of the tuberculum impar, which, together with the lateral lingual prominences, form the body of the tongue and floor of the mouth. In the oral cavity, these cysts occur most frequently in the area of the floor of the mouth and may also occur on the tongue, lips or the interior of the bone. ${ }^{4,5}$ We report a case of epidermoid cyst of the tongue with review of literature.

\section{CASE REPORT}

A female child aged 5 years presented with a swelling on the anterior part of tongue. This swelling was present since birth. It was small in size and progressed gradually to the current size of about $3 \mathrm{~cm}$ diameter. It was a well circumscribed cystic swelling, tender with a smooth surface. The swelling was embedded in the substance of the anterior tongue. There was no extension of the swelling to the sublingual part or any other regions of oral cavity. There was no discharge from the swelling and it was not causing disturbance for deglutition initially. The swelling was mostly asymptomatic, but recently started affecting speech articulation and mastication which forced the parents

Correspondence: Dr. Nilamadhaba Prusty, vSS Medical College, Burla, Odisha, 768017, India. Email: nilamadhabprusty@ gmail.com, Phone No: +91-9439482526. 
to approach doctors for treatment. Otherwise, child had a good health without any other complaints.

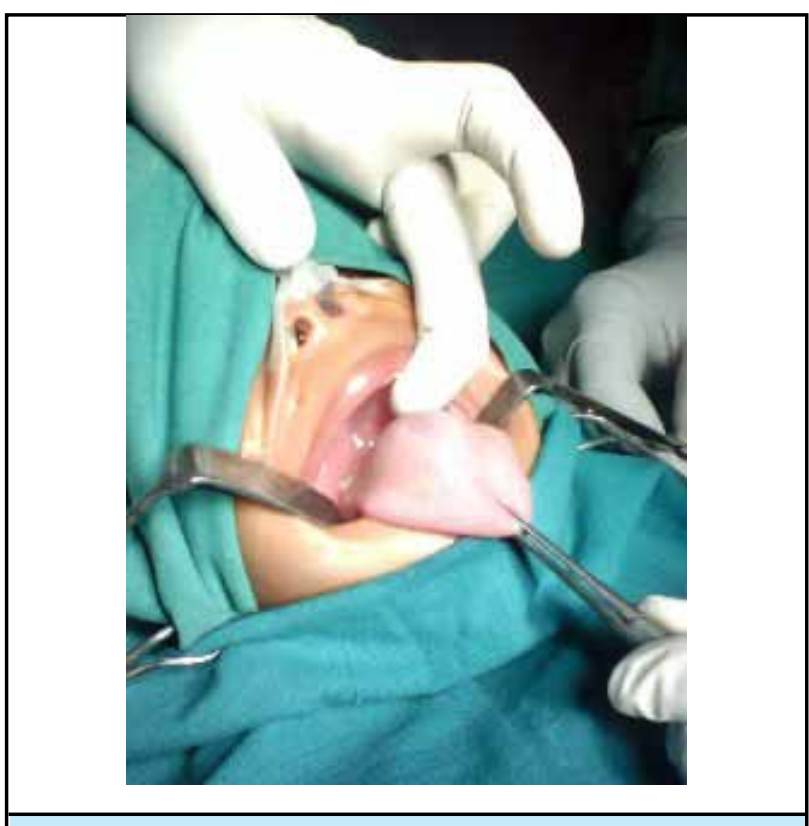

Figure 1. Pre-operative Epidermoid Cyst of Tongue.

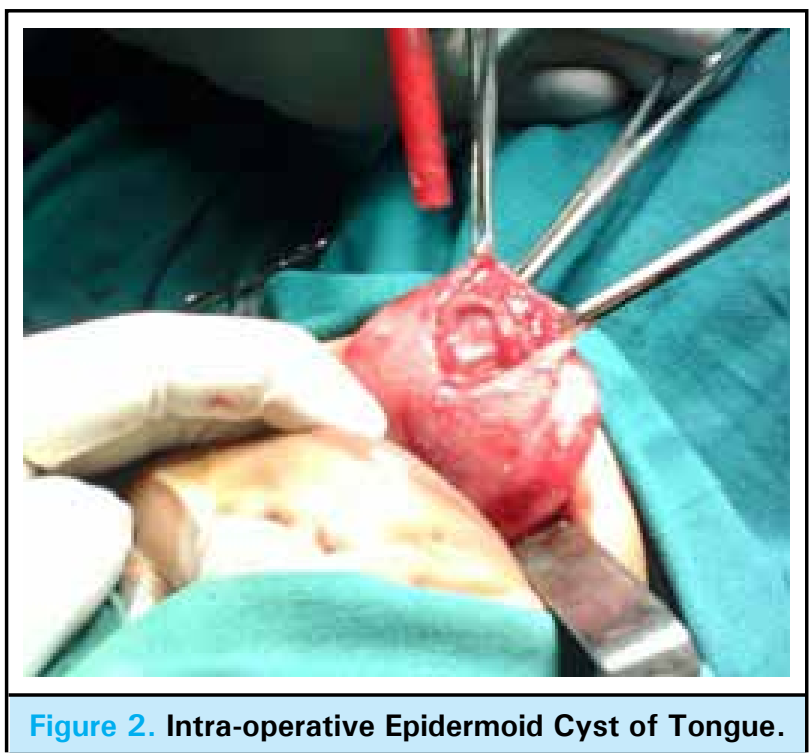

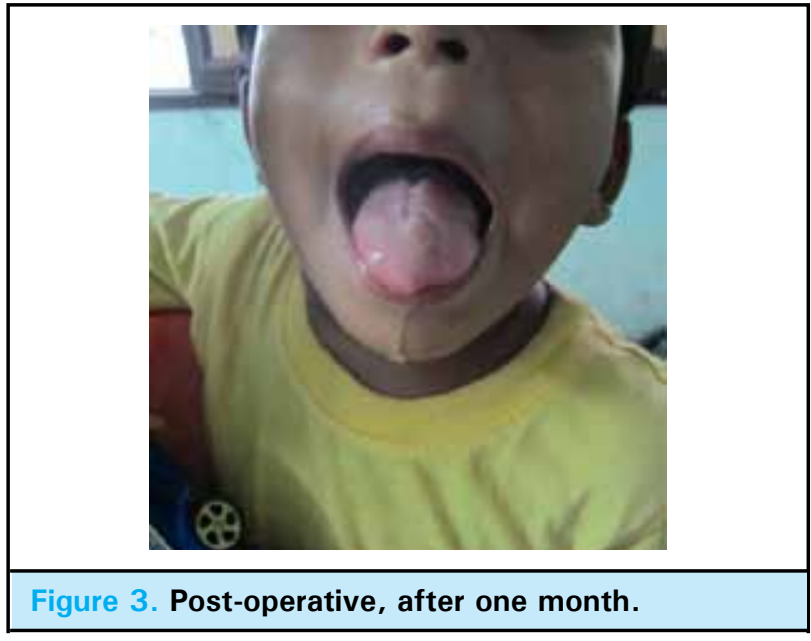

\section{DISCUSSION}

Epidermoid cyst is a congenital cyst that may appear due to trapping of ectoderm at the time of fusion of neural tube or other epithelial linings. They may also be secondary or acquired due to inclusion of epidermal elements into dermis post-traumatically or iatrogenically in which case the term epidermal inclusion cyst would be a better terminology. ${ }^{1}$ Epidermoid and dermoid cysts represent less than $0.01 \%$ of all oral cavity cysts. ${ }^{2}$ Epidermoid cysts have been described in various parts of the body, out of them only $1.6 \%$ are found in the oral cavity. ${ }^{3}$ In the oral cavity, they are commonly seen in the sublingual area, they may also be seen on the lips, tongue and bone. ${ }^{4}$ The clinical aspect is not characteristic and merely consists of a cystic swelling. As they enlarge, functional problems, such as difficulties with deglutition, speech and respiration, can be expected to occur. ${ }^{6}$ On histopathology, it is a keratin filled cavity lined by stratified squamous epithelium. ${ }^{5}$ Epidermoid cyst has to be differentiated from a dermoid cyst. Unlike a dermoid, epidermoid cyst lacks appendages like hair, sweat glands, etc. ${ }^{7}$ The treatment is complete excision of the cyst. ${ }^{1}$ In most instances, epidermoid and dermoid cysts can be enucleated. Very large cysts may require marsupialization. Recurrence is rare. ${ }^{6}$ If the epidermoid cyst of tongue is left untreated, it may grow in size and may cause discomfort in articulation, deglutition and mastication. ${ }^{4}$ Epidermoid cysts in the oral cavity may be derived from the entrapped epithelium during closure of 
first and second branchial arches which fuse during the 3rd and 4th weeks of intrauterine life. In the tongue, it is believed to be the remains of Tuberculum impar. ${ }^{8}$ Multiple epidermoid cysts may be part of Gardner syndrome. $^{9}$ Rarely, malignancies like squamous cell carcinomas, basal cell carcinoma, Bowen's disease and even mycosis fungoides have developed in epidermoid cysts. ${ }^{10}$
Epidermoid cyst of the tongue is a rare tumor of oral cavity. It presents as a swelling in the tongue with speech disturbances. Complete excision will not cause any recurrence. Possibility of syndromic association with Gardner's syndrome should be kept in mind. Malignant transformation is rare. This case is presented for its rarity and to highlight the spectrum of clinical features and management with a brief review of literature.

\section{REFERENCES}

1. Vaidya Abhishek, Sharma Arpit, Dabholkar Jyoti, Raut Abhijit. An unusual case of epidermal inclusion cyst of maxilla. International Journal of Head and Neck Surgery Jan-April 2010;1(1):43-47.

2. Tolga Kandogan, Murat Koç, Enver Vardar, Elif Selek, Ozlem Sezgin. Sublingual epidermoid cyst: A case report. J Med Case Reports 2007;1:87.

3. Turetschek K, Hospodka H, Steiner E. Case report: Epidermoid cyst of the floor of the mouth: Diagnostic imaging by sonography, computed tomography and magnetic resonance imaging. Br J Radiol 1995;68:205-07.

4. Maria Salete Nahas Pires Correa, Ricardo De Nardi Fonoff, Henrique Castilhos Ruschel, Symonne Pimentel Castro deOliveira Lima Parizotto, Fernanda Nahas Pires Correa. Lingual epidermoid cyst: Case report in an infant. Pediatr Dent 2003;25:591-93.
5. Nair DR, Pai PS, Chathurvedi P, Kumar R, Javekar SL. Epidermal inclusion cyst of the styloid process: A case report. Skull Base May 2009;19(3):225-29.

6. Katagiri Wataru, Katagiri Wataru, Chisoku Hirohisa, Sumi Tetsuro, Amekawa Shigeki, Matsumoto Ken, Yura Yoshiaki. A case of epidermoid cyst arising laterally in the root of tongue. Japanese Journal of Oral and Maxillofacial Surgery 2006;52(6):334-37.

7. Cotran RS, Kumar V, Robbins SL. Pathologic basis of disease. (5th Ed). philadelphia: WB saunders 1994;1182-83.

8. Shear Mervyn, Speight Paul M. Cysts of the Oral and Mx Facial regions (4th ed), 2007. Blackwell Munksgaard.

9. Leppard B, Bussey HJ. Epidermoid cysts, polyposis coli and Gardner's syndrome. Br J Surg May 1975;62(5):387-93

10. Lopez-Rios F, Rodriguez-Peralto JL, Castano E, Benito A. Squamous cell carcinoma arising in a cutaneous epidermal cyst: Case report and literature review. Am J Dermatopathol 1999;21:174-77. 